Journal of Applied Pharmaceutical Science Vol. 5 (12), pp. 029-034, December, 2015

Available online at http://www.japsonline.com

DOI: $10.7324 / J A P S .2015 .501205$

ISSN 2231-3354 (c) EY-NC-SA

\title{
Physicochemical quality evaluation of amoxicillin capsules produced in compounding pharmacies at Diadema, São Paulo, Brazil
}

\author{
Fúlvio Gabriel Corazza ${ }^{1 *}$, Blanca Elena Ortega Markman², Paulo César Pires Rosa ${ }^{3}$ \\ ${ }^{1}$ Departament of Hard and Earth Science, Institute of Environmental Science, Chemical and Pharmaceutical, Federal University of São Paulo Campus \\ Diadema, São Paulo, Brazil. ${ }^{2}$ Physical-Chemical Drugs Center. Adolfo Lutz Institute. Diseases Control Coordination of São Paulo, Brazil. ${ }^{3}$ Faculty of \\ Medical Sciences, Department of Pharmacology, State University of Campinas, São Paulo, Brazil.
}

\begin{tabular}{l} 
ARTICLE INFO \\
\hline Article history: \\
Received on: $27 / 08 / 2015$ \\
Revised on: $15 / 09 / 2015$ \\
Accepted on: 03/10/2015 \\
Available online: $27 / 12 / 2015$ \\
\hline Key words: \\
Amoxicillin. Capsules. \\
Quality Control. \\
Compounding Pharmacies.
\end{tabular}

\begin{abstract}
The evaluation of the physicochemical quality of amoxicillin $(500 \mathrm{mg})$ capsules produced in Compounding Pharmacies at Diadema - SP - Brazil, was performed by comparing these capsules with reference, generic and similar drugs, through the dissolution, assay, average weight, water content analysis, all according to the pharmacopeial methodology. The compounded drug samples were acquired on 8 different Compounding Pharmacies of Diadema (M1, M2, M3, M4, M5, M6, M7, M8), and five (reference, generic and similar) drug samples (R, G1, G2, S1, S2) produced by distinct pharmaceutical industries were obtained from different Drugstores also at the same area. The samples were evaluated using the methodology proposed by the American and Brazilian Pharmacopoeia. All samples were approved in the dissolution and water content assay. Only samples R and S1 were approved assay of dose. Samples M3, M4 and S1 were disapproved in the average weight assay. The non-fulfillment of the Brazilian Good Manufacturing Practices recommended procedures for industries and compounding pharmacies show the need for improvements in the overall drug quality control manufacturing process of finished products in consonance with the actual health legislation, guaranteeing access to safe, effective medicines, control of bacterial resistance and rational use of antibiotics.
\end{abstract}

\section{INTRODUCTION}

The penicillin antibiotics that includes amoxicillin are widely known (Paganotti et al., 2013; von Nussbaum et al., 2006) however, their inappropriate use brings favorable conditions to spreading of antibiotic resistant bacteria (Goll et al., 2013). The development of antibiotic resistance might be favored by non-microbial factors, such as wrong choice of type and dosage of antibiotic; ease of acquiring non-prescription drugs; non-adherence to the entire course of treatment and use of lowquality antibiotics (Lewis et al., 2011). The advantages of compounding drugs range from lower cost to a medication personalized for an individual patient. However, it is essential to ensure the quality of compounded and provided drugs to the

\footnotetext{
* Corresponding Author

Fúlvio Gabriel Corazza, Departament of Hard and Earth Science, Institute of Environmental Science, Chemical and Pharmaceutical, Federal University of São Paulo Campus Diadema, São Paulo, Brazil. Email: fulvio.corazza@unifesp.br
}

population (Oliveira Júnior et al., 2011). The increasing number of compounding pharmacies has led to the development of studies analyzing the customized medications, thus allowing to emerge specific data related to the compounded drug quality. These data may display the actual security circumstances in which these products are being provided to the population (Zarbielli et al., 2007). The concern over the compounding of antibiotics is even greater considering that bioavailability can be affected by problems in formulation and compounding thus generating therapeutic failure along with the possibility of bacterial resistance, which is now as a worldwide public health problem (Dias et al., 2011). Gianotto et al. (2008), analyzed three compounded $20 \mathrm{mg}$ hydrochloride fluoxetine capsules, purchased in eighteen compounding pharmacies at Londrina (Brazil, Paraná), and compared weight variation test, assay of dose and content uniformity with of the industrialized product. The compounded capsules that met the specifications of the tests were $63 \%$. Markman et al. (2010), evaluated 18 capsules of $40 \mathrm{mg}$ simvastatin from four cities of São Paulo's compounding pharmacies. 
The identification and quantification of compounded capsules analysis were based on the Brazilian Pharmacopoeia and in the chromatography method, both optimized and validated in accordance with national and international standards.

The capsules average weight ranged from $70 \mathrm{mg}$ to 316 $\mathrm{mg}$; four samples presented weight variation outside the specification. The simvastatin capsules content was according to the specification in 11 samples; the content of six samples ranged from $4 \%$ to $87 \%$ in declared value, disregarding the content requirements of active ingredient; drug content and weight uniformity analysis were not performed. In the content uniformity test, 15 samples showed values lower than $85 \%$ and relative standard deviations greater than 6\%; Three compounding pharmacies met the specification on essay.

In the dissolution test, eight samples results were unsatisfactory on the first stage, and the remaining samples showed inconclusive results. This study revealed the lack of quality of simvastatin capsules produced by some compounding pharmacies. Defáveri et al. (2012) evaluated identification, weight variation, disintegration, dissolution, unit dose uniformity and content determination by comparing capsules of sibutramine hydrochloride $(10 \mathrm{mg})$, compounded at five different pharmacies (A, B, C, D, E) of Santa Maria (Rio Grande do Sul, Brazil), and reference drug.

The reference drug and the compounded capsules from pharmacies B, C and D fulfilled the specifications of all tests. The compounded capsules from A were rejected on the disintegration and dissolution tests, and those from $\mathrm{E}$ were also rejected on the unit dose uniformity. The quality of medicines is vital to patient safety.

Drug quality control is necessary and intended to ensure the efficacy, safety and quality of medicines, a crucial role of any pharmacist for public health (Corrêa et al., 2014). Despite the increasing role of National Health Surveillance Agency in Brazil, still pharmaceutical products outside the standards of quality infiltrate the Brazilian market exposing the population to an unacceptable risk (Gurgel et al., 2008).

The knowledge and control of bacterial resistance are essential for a rational and coordinated administration of antibiotics (Janebro et al., 2008) and in such way, when properly performed drug production and drug quality control can benefit greatly, guaranteeing access to safe and effective medicines (Andrade et al., 2013) and notably antibiotics, which when suitable for a well-established medical condition, can delay the development of bacterial resistance (Gurgel et al., 2008).

This study focused on evaluating the physicochemical quality of amoxicillin $500 \mathrm{mg}$ capsules produced in Compounding Pharmacies at Diadema, comparing these with reference, generic and similar drugs by official compendium analysis of recommended parameters, such as dissolution test, assay, average weight and water content; hence verifying the physicochemical compliances required of retailed drugs.

\section{MATERIALS AND METHODS}

Amoxicillin ( $86.3 \%$ purity) was used as the standard reference kindly donated by Medley pharmaceutical company. The amoxicillin compounded capsules (500 mg) (M1, M2, M3, M4, M5, M6, M7 e M8) were purchased from 8 randomly selected compounding pharmacies at Diadema, São Paulo, Brazil. The reference (R), generic (G1 and G2) and similar (S1 and S2) drugs capsules (500 mg) manufactured by different pharmaceutical industries were purchased from randomly selected drug stores. All purchased capsules content were stated as $500 \mathrm{mg}$ per unit and were carried out dissolution test, assay, average weight and water content. All samples used were acquired through a medical prescription.

\section{Dissolution test}

The dissolution were tested in 6 units samples of each R, G1, G2, S1, S2, M1, M2, M3, M4, M5, M6, M7 and M8, according to the Brazilian Pharmacopoeia (Brazil, 2010b), using $900 \mathrm{~mL}$ distilled water (water purification system by reverse osmosis, Model OS20 LZ Gehaka ${ }^{\circledR}$ ) as the dissolution medium in baskets at $100 \mathrm{rpm}$ for 90 minutes at $37 \pm 1^{\circ} \mathrm{C}$. After dissolution, 5 $\mathrm{mL}$ of each sample were filtered on cellulose membrane with porosity of $0.20 \mu \mathrm{m}$ (Pall Corporation ${ }^{\circledR}$ ) to a $10 \mathrm{~mL}$ volumetric flask and the remaining volume completed with the diluent. The absorbance readings were checked with UV-Vis spectrophotometry technique (model Evolution 201, UV-visible Thermo Scientific $\left.{ }^{\circledR}\right)$ at $272 \mathrm{~nm}$ wavelength. The calculation and determination of the amoxicillin liberated amount on the dissolution tests were based on the comparison between the absorbance readings and reading obtained with the standard solution at a concentration of $0.275 \mathrm{mg} \mathrm{mL}^{-1}$.

\section{Assay of dose}

The determination of the amoxicillin content was performed according to criteria established by the US Pharmacopoeia (Usp, 2009), described below.

The diluent solution were prepared by weighing $13.61 \mathrm{~g}$ of monobasic potassium phosphate $\left(\mathrm{Merck}^{\circledR}\right)$ on an analytical scale (Shimadzu ${ }^{\circledR}$ model AY220), and then dissolving in $2000 \mathrm{~mL}$ of ultra purified water (water purification system by reverse osmosis, model OS20 LZ coupled to a ultra purifier, model Master System P\&D Gehaka ${ }^{\circledR}$ ), adjusting the $\mathrm{pH}$ to 5.0 (pH Meter $\mathrm{pH} 21$, Hanna Instruments $^{\circledR}$ ) with a potassium hydroxide solution (Merck ${ }^{\circledR}$ ) $45 \%$ $(\mathrm{v} / \mathrm{v})$, and lastly filtering the solution in a $0.20 \mu \mathrm{m}$ porosity nylon membrane (Pall Corporation ${ }^{\circledR}$ ).

The standard amoxicillin solution was prepared by weighing $60.1 \mathrm{mg}$ of amoxicillin in analytical scale (model AY220, Shimadzu ${ }^{\circledR}$ ), transferring to a volumetric flask $50 \mathrm{~mL}$ and completing the volume of the flask with the diluent solution. The solution was homogenized in an ultrasonic bath (Altsonic Clean ${ }^{\circledR}$ ) for 10 minutes, obtaining the concentration of $1.202 \mathrm{mg} \mathrm{mL}^{-1}$, of which an $10 \mathrm{~mL}$ aliquot were placed into a $50 \mathrm{~mL}$ volumetric flask 
and completed with the diluent to volume resulting in a $0.2404 \mathrm{mg}$ $\mathrm{mL}^{-1}$ concentration.

The amoxicillin samples solutions were obtained initially by removing the content of each 20 capsules samples, and weighing in analytical balance (AY220 model, Shimadzu ${ }^{\circledR}$ ). Then, the homogenized content from the capsules were again weighed in analytical balance (model AY220, Shimadzu ${ }^{\circledR}$ ) to approximately $60 \mathrm{mg}$ and transferred to $50 \mathrm{~mL}$ volumetric flask, completing the volume with diluent solution, and homogenized in an ultrasonic bath (Altsonic Clean ${ }^{\circledR}$ ) for 10 minutes. From the resulting solution a $10 \mathrm{~mL}$ aliquot were transferred to $50 \mathrm{~mL}$ volumetric flask and its volume were completed with diluent. Diluent: diluent solution of monobasic potassium phosphate $\left(\right.$ Merck $\left.^{\circledR}\right)$ at a concentration of 6.8 $\mathrm{g} \mathrm{L} \mathrm{L}^{-1}$, adjusting its $\mathrm{pH}$ to 5.0 (pH Meter $\mathrm{pH} 21$, Hanna Instruments $^{\circledR}$ ) with a potassium hydroxide solution $\left(\right.$ Merck $\left.^{\circledR}\right) 45 \%$ (v/v). Standard solution: standard amoxicillin solution concentration $0.2404 \mathrm{mg} \mathrm{mL}^{-1}$.

Sample solutions: solutions with concentration of 0.24 $\mathrm{mg} \mathrm{mL} \mathrm{m}^{-1}$ homogenized in an ultrasonic bath (Altsonic Clean ${ }^{\circledR}$ ) were obtained from $60 \mathrm{mg}$ of weighed and homogenized contents of 20 amoxicillin capsules.

The standard amoxicillin solution and the sample solutions were both early filtered on nylon membrane with porosity of $0.20 \mu \mathrm{m}$ (Pall Corporation ${ }^{\circledR}$ ) and then $10 \mu \mathrm{L}$ of each solution were injected, respectively, in quintuplicate and quadruplicate, in the chromatograph.

Chromatographic conditions: High Performance Liquid Chromatography (HPLC) model Thermo Scientific ${ }^{\circledR}$ equipped with model Accela ${ }^{\mathrm{TM}} 600$ pump, $230 \mathrm{~nm}$ wavelength UV-Vis detector model Accela ${ }^{\mathrm{TM}}$ PDA chromatography data system software ChromQuest ${ }^{\mathrm{TM}} 5.0$ and Accela ${ }^{\mathrm{TM}}$ AS autosampler, chromatography column oven Hypersil ${ }^{\mathrm{TM}}$ ODS-2 (250 mm x 4.6 mm, $5 \mu \mathrm{m}$ ) model ThermoEletro ${ }^{\circledR}, 25^{\circ} \mathrm{C}$, acetonitrile and diluent $\left(\right.$ Merck $\left.^{\circledR}\right)(96: 4)$ as mobile phase at $1.0 \mu \mathrm{L} \mathrm{min}{ }^{-1}$ flow rate.

\section{Average weight}

The average weight determination of the content of M1, M2, M3, M4, M5, M6, M7, M8, R, G1, G2, S1 and S2 samples were performed according to method and criteria of the Brazilian Pharmacopoeia (Brazil, 2010a). Firstly, 20 amoxicillin capsules, containing $500 \mathrm{mg}$ each, were individually weighed in analytical balance (AY220 model, Shimadzu ${ }^{\circledR}$ ). Then, the contents of each capsule were removed and the capsules cleaned properly and empty individually weighed again. Lastly, the weight of each capsules were determined by the weight difference between full and empty capsules. The average weight (AW), standard deviation (SD) and coefficient of variation (CV) were determined by the weight of each capsule.

\section{Water content}

The water content determination was performed at the Antibiotics Section, Drug Service, Adolfo Lutz Institute, São Paulo, Brazil according to criteria established by the Brazilian Pharmacopoeia (Brazil, 2010a).

\section{RESULTS AND DISCUSSION}

\section{Dissolution test}

Table 1 shows the amoxicillin dissolved in the dissolution medium using the previous absorbance results and the Equation 1.

$\frac{S A \times S A M \times S P \times S D F}{S T A \times S T D F \times A T D}=\%$ dissolved amoxicillin per capsule

Where: SA: Sample Absorbance; SAM: Standard Amoxicillin Mass (mg); SP: Standard Purity (\%); SDF: Sample Dilution Factor; STA: Standard Absorbance; STDF: Standard Dilution Factor; ATD: Amoxicillin Therapeutic Dose per Capsule (mg).

Table 1: Dissolution tests results of amoxicillin capsules $(500 \mathrm{mg})$.

\begin{tabular}{ccc}
\hline Samples & $\begin{array}{c}\text { Percentage mean of dissolved } \\
\text { amoxicillin/capsule }\end{array}$ & SRD $(\%)^{*}$ \\
\hline R & 98.8 & 1.3 \\
G1 & 93.6 & 3.3 \\
G2 & 103.8 & 2.8 \\
S1 & 106.9 & 4.2 \\
S2 & 96.9 & 6.4 \\
M1 & 104.0 & 3.9 \\
M2 & 99.2 & 5.1 \\
M3 & 98.0 & 6.2 \\
M4 & 106.2 & 6.7 \\
M5 & 97.1 & 7.5 \\
M6 & 99.8 & 3.2 \\
M7 & 90.8 & 4.2 \\
M8 & 101.7 & 4.6 \\
\hline
\end{tabular}

*Where RSD\% is the relative standard deviation given as percentage.

The dissolution test determines the amount of active ingredient dissolved into the dissolution medium when the product is subjected to appropriate apparatus and experimental conditions. The result is a percentage of that labeled in the product (Brazil, 2010a).

The Brazilian Pharmacopoeia (Brazil, 2010b) establishes the tolerance limit as not less than $80 \%$ of the declared released amount into the dissolution medium in 90 minutes. Table 1 shows all approved samples. As reported by Souza et al. (2009), the results agree with the fact that amoxicillin is categorized as class III drug according to the biopharmaceutical classification system, and like so facilitating the adjuvant selection for capsule filling.

All samples, aside from sample R, show high RSD\% values; implying that mean of values are not precise and the values of dissolution medium per capsule is not an uniform amoxicillin distribution percentage, and thus interfering on the drug formulation by technical limitations during the capsules production, heterogeneity distribution of the active ingredient and excipients (Muniz et al., 2012; Sant'Anna et al., 2011).

\section{Assay of dose}

Table 2 shows the amoxicillin content in the amoxicillin capsules $(500 \mathrm{mg})$ using the Equation 2.

$$
\frac{P A R \times S A M \times S P \times A W \times S D F}{S A P \times S M \times S T D F \times A T D}=\% \text { of amoxicillin }
$$


Where: PAR: Peak Area Ratio; SAM: Standard Amoxicillin Mass (mg); SP: Standard Purity (\%); $A W$ : Average Weight (mg); SDF: Sample Dilution Factor; SAP: Standard Amoxicillin Peak Area Ratio; SM: Sample Mass (mg); STDF: Standard Dilution Factor; ATD: Amoxicillin Therapeutic Dose per Capsule (mg).

The chromatography system evaluation parameter values: retention factor: 1.20 ; asymmetry $(10 \%)$ : 1.16 ; number of theoretical plates: 6273. The previous parameter values comply with the chromatography system suitability and Usp (2009) parameters.

Table 2: Assay results for amoxicillin capsules (500 mg).

\begin{tabular}{cc} 
Sample & Mean of the amoxicillin content $(\%)$ \\
\hline R & 119.3 \\
G1 & 84.6 \\
G2 & 88.7 \\
S1 & 90.1 \\
S2 & 83.4 \\
M1 & 77.5 \\
M2 & 74.2 \\
M3 & 61.7 \\
M4 & 81.6 \\
M5 & 66.9 \\
M6 & 74.6 \\
M7 & 67.8 \\
M8 & 80.5 \\
\hline
\end{tabular}

The content determination is essential to quality evaluation of pharmaceutical drugs (Pasa et al., 2008), for it determinates the amount of active ingredient administered into an organism (Defáveri et al., 2012).

It is therapeutically crucial that antibiotic drugs to reach effectively proper concentration at the infection site (Silveira et al., 2006).

The amoxicillin capsules contain the equivalent of not less than $90 \%$ and not more than $120 \%$ of the labeled amount of amoxicillin (Usp, 2009); hence only capsules of samples R and S1 satisfy the required parameters.

The manufactured by different pharmaceutical industries samples have superior amoxicillin content when compared to the compounded samples. The $\mathrm{R}$ sample has the topmost amoxicillin content percentage.

Laporta et al. (2013), found 2 inadequate samples regarding the assay of dose of 7 metformin hydrochloride capsules compounded by 7 different pharmacies at a south region city in Brazil.

In relation to content evaluation, Markman et al. (2010) found among 18 simvastatin (40 mg) compounded samples, 6 of them presented $4 \%$ to $87 \%$ content variation of active ingredient inappropriately declared.

Bonfilio et al. (2014) conducted physicochemical and microbiological analysis survey on 2347 compounded products samples from 117 different pharmacies at 49 Brazilian cities, between January 2010 and December 2011. Among these samples, $21.4 \%$ were not conform to specified physicochemical requirements. Other analysis such as average weight and dissolution were found to be nonconforming, highlighting the assay of dose which had the biggest indicators of nonconformity. The antibacterial samples had the greatest rate in the physicochemical nonconformity analysis indicators.

Azevedo et al. (2008) states that although the chromatography method has a relatively simple technique involved in its execution, it also has the distinction of being the most sensitive method allowing the quantification of a certain drug.

Comparing the results obtained from UV-Vis spectrophotometer on the dissolution test, and HPLC on the assay of dose, it is possible to notice a significant discrepancy in the number of samples disapproved. According to Oliveira et al. (2010), this may be due to the fact that the fundamentals of HPLC are based on the separation of substances in a sample by interaction of these with the mobile phase and the active sites of the column. This ensures a greater selectivity in the determination of the drug, especially when compared to the spectrophotometer technique, in which the readings of the samples comprises all components with absorptive value near or coincident to the same wavelength of the analyzed active ingredient. Therefore, the method must be carefully selected and must provide selectivity, reproducibility and sensitivity in order to avoid inconsistent results related to the actual product formulation.

The unsatisfactory results are worrisome for the reason that drugs administration with active ingredient below the labeled concentration can result in therapeutic failure, which compromises the patient clinical status (Lima et al., 2008) and moreover can lead to selection of resistant bacteria (Gurgel et al., 2008).

Regardless of production scale, these results point to the need of reviewing the manufacturing process, involving raw materials analysis, weighing, blending, encapsulation and storage, in order to obtain drugs with quality, ensuring their efficacy and a safe treatment (Pissatto et al., 2006).

\section{Average weight}

The results shown on Table 3 were analyzed according to the specifications of the Brazilian Pharmacopoeia (2010a), which determines the individual variation of capsules content average weight permitted to be $\pm 7,5 \%$, tolerating maximum variations of two units outside the original range, and yet no unit must be above or below twice the indicated percentage.

The coefficient of variation indicates technical accuracy when lower than 5\%, and therefore higher CV shows the need to improve the manufacturing process (Brazil, 2003). The samples CV show values under 4\%; an important indicator of powder homogeneous distribution in production stage, ensuring that quality is built into the final product (Andrade et al., 2013).

According to the specifications of the Brazilian Pharmacopoeia (2010a), samples S1, M3 and M4 were disapproved in the average weight assay. Sample S1 has one unit below the DLL; M3 sample has one unit above DHL and one unit below LL; and M4 sample has one unit above DHL. 
Table 3: Average weight results.

\begin{tabular}{|c|c|c|c|c|c|c|c|c|c|}
\hline Sample & $\begin{array}{l}\text { AW } \\
(\mathbf{m g})\end{array}$ & SD & CV (\%) & $\begin{array}{l}\text { HL } \\
(\mathrm{mg})\end{array}$ & $\begin{array}{l}\text { DHL } \\
(\mathrm{mg})\end{array}$ & $\begin{array}{l}\mathbf{L L} \\
(\mathrm{mg})\end{array}$ & $\begin{array}{l}\text { DLL } \\
(\mathrm{mg})\end{array}$ & $\begin{array}{l}\text { Number of units off the specified } \\
\text { limit }\end{array}$ & Result \\
\hline $\mathrm{R}$ & 580.7 & 6.92 & 1.2 & 624.3 & 667.8 & 537.1 & 493.6 & 0 & Approved \\
\hline G1 & 581.3 & 9.39 & 1.6 & 624.9 & 668.5 & 537.7 & 494.1 & 0 & Approved \\
\hline $\mathrm{G} 2$ & 594.5 & 11.4 & 1.9 & 639.1 & 683.7 & 549.9 & 505.3 & 0 & Approved \\
\hline S1 & 620.5 & 24.7 & 4.0 & 667.0 & 713.6 & 574.0 & 527.4 & 1 & Disapproved \\
\hline $\mathrm{S} 2$ & 613.4 & 3.04 & 0.5 & 659.4 & 705.4 & 567.4 & 521.4 & 0 & Approved \\
\hline M1 & 574.4 & 13.8 & 2.4 & 617.5 & 660.6 & 531.3 & 488.2 & 0 & Approved \\
\hline M2 & 623.3 & 11.1 & 1.8 & 670.0 & 716.8 & 576.6 & 529.8 & 0 & Approved \\
\hline M3 & 473.4 & 18.3 & 3.9 & 508.9 & 544.4 & 437.9 & 402.4 & 2 & Disapproved \\
\hline M4 & 609.2 & 23.2 & 3.8 & 654.9 & 700.6 & 563.5 & 517.8 & 1 & Disapproved \\
\hline M5 & 557.6 & 14.6 & 2.6 & 599.4 & 641.2 & 515.8 & 474.0 & 0 & Approved \\
\hline M6 & 700.3 & 11.6 & 1.7 & 752.8 & 805.3 & 647.8 & 595.3 & 0 & Approved \\
\hline M7 & 554.7 & 11.0 & 2.0 & 596.3 & 637.9 & 513.1 & 471.5 & 0 & Approved \\
\hline M8 & 644.9 & 23.4 & 3.6 & 693.3 & 741.6 & 596.5 & 548.2 & 0 & Approved \\
\hline
\end{tabular}

AW: Average Weight; SD: Standard Deviation; CV: Coefficient of Variation; HL: Higher Limit; DHL: Double of the Higher Limit; LL: Lower Limit; DLL:

Double of the Lower Limit.

The dose uniformity and active ingredient homogeneity inside the capsules relate directly to the necessary approval requirements of the average weight assay. Once a known weight difference is distinguished it is impossible to assure the active ingredient content of all capsules (Marques-Marinho et al., 2009; Scheshowitsch et al., 2007).

\section{Water content}

The water content of the amoxicillin capsules $(500 \mathrm{mg})$ are shown in Table 4

Table 4: Amoxicillin samples water content.

\begin{tabular}{ccc}
\hline Sample & Mean of the water content $\mathbf{( \% )}$ & Result \\
\hline R & 12.8 & Approved \\
G1 & 8.7 & Approved \\
G2 & 1108 & Approved \\
S1 & 9.8 & Approved \\
S2 & 8.0 & Approved \\
M1 & 10.6 & Approved \\
M2 & 5.1 & Approved \\
M3 & 5.3 & Approved \\
M4 & 5.4 & Approved \\
M5 & 9.9 & Approved \\
M6 & 10.6 & Approved \\
M7 & 9.4 & Approved \\
M8 & 10.0 & Approved \\
\hline
\end{tabular}

Table 4 shows all approved samples with water content under $14.5 \%$ in agreement with the Brazilian Pharmacopeia (Brazil, 2010b).

The results regarding samples water content certify patient safety and drug efficacy, concealing drug catalytic degradation reactions of water (Silva et al., 2009).

\section{CONCLUSION}

All samples were approved in the dissolution and water content assay. Only samples R and S1 were approved assay of dose. Samples M3, M4 and S1 were disapproved in the average weight assay.

The no fulfillment of the Brazilian Good Manufacturing Practices recommended procedures for industries and compounding pharmacies regarding the assay of dose and average weight indicate the need for improvements in the overall drug quality control manufacturing process of finished products in consonance with the actual health legislation.

\section{ACKNOWLEDGEMENTS}

The authors would like to thank the Adolfo Lutz Institute - Brazil, the Laboratory of Pharmacotechnical and Cosmetology, Laboratory of Natural and Synthetics Ingredients - Federal University of São Paulo Campus Diadema, and the Thermo Scientific ${ }^{\circledR}$.

\section{REFERENCES}

Andrade DF, Carvalho JS, Freitas MB. Quality of fluoxetine capsules available from the Sistema Único de Saúde: in vitro study of conditions used in dissolution test. J Basic Appl Pharm Sci, 2013; 34(2): 199-205.

Azevedo RCP, Ribeiro GP, Araújo MB. Development and validation of dissolution test for captopril in capsules by HPLC. Braz $\mathrm{J}$ Pharm Sci, 2008;44(2):261-69.

Bonfilio R, Santos OMM, Novaes ZR, Matinatti ANF, Araújo MB. Physicochemical and microbiological quality of 2347 samples of medications compounded in Brazil in 2010 and 2011. J Basic ApplPharmSci, 2013;34(4):527-35.

Corrêa JCR, Vanzela NM, Silva TD, Vianna-Soares CD, Salgado HRN. Assessment of the quality of compounded fluconazole capsules marketed in the region of Araraquara (SP, Brazil). J Basic Appl Pharm Sci, 2014;35(2):257-61.

Defáveri MAS, Laporta LV, Santos MR, Silveira RL, Alves MP, Rubim AM. Quality evaluation of sibutramine hydrochloride capsules compounded in pharmacies. Disc Scientia. Series: Health Sciences, 2012; 13(1):71-83.

Dias ILT, Almeida RLB, Carrieiro EF. Evaluation of quality of amoxicillin capsules produced in compounding pharmacies. Electron $\mathbf{J}$ Pharm, 2011; 8(4): 27-40.

Gianotto EAS, Machado HT, Miglioranza B, Fregonezi-Nery MM. Quality of fluoxetine hydrochloride capsules compounded in pharmacies. Lat Am J Pharm, 2008; 27(5):727-33.

Goll AS, Faria MGI. Bacterial resistance as a result of use unsuitable of antibiotics. Braz J Surg Clin Res, 2013;5(1):69-72.

Gurgel TC, Carvalho WS. The pharmaceutical assistance and the increase in bacterial resistance to antimicrobials. Lat Am J Pharm, 2008; 27(1):118-23.

Janebro DI, Belém LF, Pinto DS, Tomaz ACA, Ximenes LMA. Use of penicillin in the pediatric area of a hospital in Campina Grande, Paraíba, Brazil. Lat Am J Pharm, 2008;27(1):4-9. 
Laporta LV, Brum TF, Pons Júnior FR, Santos, MR, Gonçalves CA. Validation of analytical method for quality control of compounded metformin hydrochloride capsules. J Basic Appl Pharm Sci, 2013; 34(2): $235-55$.

Lewis DA, Lukehart SA. Antimicrobial resistance in Neisseria gonorrhoeae and Treponema pallidum: evolution, therapeutic challenges and the need to strengthen global surveillance. Sex Transm Infect, 2011; 87(Suppl 2): ii39-43.

Lima APCS, Gallani NR, Toledo MI, Lopes LC. Use of Pharmacy Banafits Management (PBM) system to describe the profile of antibiotic prescription and purchase. Braz J Pharm Sci, 2008;44(2):215-23.

Marques-Marinho FD, Vianna-Soares CD, Carmo VAS, Campos LMM. Quality evaluation of pantoprazole gastro-resistant compounded capsules. Lat Am J Pharm, 2009; 28(6):899-906.

Markman BE, Rosa PC, Koschtschak MR. Assessment of the quality of simvastatin capsules from compounding pharmacies. Rev Saúde Pública, 2010; 44(6):1055-62.

Ministry of Health (Brazil). National Health Surveillance Agency. Guide to Analytical and Bioanalytical Methods Validation. Resolution 899, 2003; May 29.

Muniz GSO, Oliveira Júnior AZ, Garcia MTJ. Hard gelatin capsules of nimesulide: the influence of sodium starch glycolate and its concentration, on the dissolution of the drug. J Basic Appl Pharm Sci, 2012; 33(3):361-71

National Health Surveillance Agency. 2010. Brazilianpharmacopeia. General methods. $5^{\text {th }}$ ed. Brasília. Brazil . pp. 545. National Health Surveillance Agency. 2010. Brazilianpharmacopeia. General methods. $5^{\text {th }}$ ed. Brasília. Brazil . pp. 853.

Oliveira DM, Markman BEO, Uessugui O, Wu EM, Magnelli RF. Fluconazole capsule dissolution test: problems encountered in UV spectrophotometry determination. J Basic Appl Pharm Sci, 2010; 31(2): 211-13.

Oliveira Júnior FG, Sá FS, Pianetti GA, César IC. Comparison of high performance liquid chromatography and non-aqueous titration for the quantitation of alprazolam in compounded capsules. J Basic Appl Pharm Sci, 2011; 32(3):95-8.

Paganotti AM, Reis RA, Crozatti MTL, Silva ATA, Fegadolli C. Prescription of antibiotics to children in winter at a basic health unit in the state of São Paulo, Brazil. J Basic Appl Pharm Sci, 2013;34(3):441-47.
Pasa CR, NemesAPM, Stuhrk CC, Amaral MS, Kassab NM. Antihypertensive drugs with captopril, propranolol and losartan analysis prepared by pharmacists in Campo Grande-MS. Pharm Braz J, 2008;89(4):322-26.

Pissatto S, Prado JN, Morais EC, Foppa T, Murakami FS, Silva MAS. Evaluation of quality of fluoxetine hydroclhoride capsules. Bonaerense Pharm Acta, 2006; 25(4):550-4.

Sant'Anna VR, Rosa PCP, Dias ILT. Pharmaceutical development of simvastatin capsules. Health Multidiscip J, 2011;3(6):214 .

Scheshowitsch K, Pereira A, Cruz A, Silva MAS, Stulzer HK. Quality evaluation and dissolution profile of piroxicam manipulated capsules. Lat Am J Pharm, 2007;26(5):645-651.

Silva KER, Alves LDS, Soares MFR, Passos RCS, Faria AR, RolimNeto PJ. Stability models assessing of drugs and drug products for pharmaceutical industry. J Basic Appl Pharm Sci, 2009;30(2):129-35.

Silveira GP, Nome F, Gesser JC, Sá MM, Terenzi H. Recent achievements to combat bacterial resistance. New Chem, 2006;29(4):84455 .

Souza KJ, Aléssio PV, Gomes AJPS. Development of specific excipient for compounded nifedipine capsules. Part I. J Basic Appl Pharm Sci, 2009;30(3):257-61

United States Pharmacopeial Convention.The United States Pharmacopeia USP 32:The National Formulary: NF 27. 32th ed. Rockville, 2009;(2).

von Nussbaum F, Brands M, Hinzen B, Weigand S, Häbich D. Antibacterial natural products in medicinal chemistry--exodus or revival? AngewChemInt Ed Engl, 2006; 45(31):5072-129.

Zarbielli MG, Macedo S, Mendez AL. Quality evaluation of the piroxicam capsules manipulated in the compounding pharmacies in the city of Erechim (RS). Infarma, 2007; 19(1/2):17-23.

\section{How to cite this article:}

Corazza FG, Markman BEO, Rosa PCP. Physicochemical quality evaluation of amoxicillin capsules produced in compounding pharmacies at Diadema, São Paulo, Brazil. J App Pharm Sci, 2015; 5 (12): 029-034. 